\title{
Structural correlates of neurological signs in Huntington's disease: a quantitative approach
}

\author{
E.A. Loh, J.K.A. Roberts ${ }^{1}$ and E. Mohr \\ Institute of Mental Health Research, Royal Ottawa Hospital/University of Ottawa, \\ Neuropsychiatry Program and Neurodegenerative Disorders Branch, Ottawa, Ontario, \\ Canada, K1Z $7 K 4$ \\ ${ }^{1}$ Present address: Department of Psychiatry, Calgary General Hospital, 841 Centre Avenue \\ East, Calgary, Alberta, Canada, T2E OA1 \\ Correspondence to: E. Mohr, Institute of Mental Health Research, Royal Ottawa Hospital/ \\ University of Ottawa, 1145 Carling Avenue, Ottawa, Ontario, Canada, K1Z 7K4
}

\begin{abstract}
Huntington's disease (HD) is a genetically transmitted disorder associated with atrophy of the basal ganglia. Studies of the neuroanatomical correlates of $\mathrm{HD}$ have focused primarily on the anterior areas of the basal ganglia and on establishing an association between structural changes resulting from the presence and course of the illness. The objective of the present study was to assess the value of measurements of the third ventrical and lentiform regions. Computed tomographic (CT) brain scan measures of the basal ganglia of patients in the "early" and "late" stages of the disease were correlated with scores on a quantified neurological examination (QNE) and compared with scans of age-matched control groups. Basal ganglia atrophy was assessed by two conventional "anterior" measures: the maximal distance between the frontal horns of the lateral ventricles (FH) and the minimum distance between the caudate nuclei (CC), and two measures of more "posterior" regions: the width of the third ventricle (3V), and a measure of the lentiform regions (LENTI). In the group of patients with HD, CT scan measures were strongly correlated with disease duration. Further, in the "late" group, all CT measures were significantly correlated with QNE scores, with the two "posterior" measures being equally, if not more strongly correlated with QNE scores than the conventional "anterior" measures. Separate correlations of the CT indices of atrophy and QNE scores in the "early" and "late" HD groups revealed relationshps between basal ganglia atrophy and motor abnormality consistent with earlier reports.
\end{abstract}

Keywords: Basal ganglia - Brain - CT scan - Huntington's disease - Neurological examination - Quantification

\section{INTRODUCTION}

Considerable evidence now suggests that motor deficits observed in the progression of Huntington's disease (HD) are related to basal ganglia deterioration (Bruyn, 1968, 1973). Neuropathological studies examining structural alterations of the basal ganglia related to the progression of HD have indicated that atrophy appears to start in the rostromedial caudate regions and, with advancing disease, extends laterally and caudally into the putamen. Atrophy of the pallidal regions eventually becomes apparent in the most severe cases (Roos et al., 1985; Vonsattel et al., 1985). Computed tomographic (CT) investigations have been used to evaluate the progression of basal ganglia atrophy associated with HD. Such studies have commonly focused on measures of the anterior caudate regions and have confirmed that these regions atrophy with disease progression (Terrence et al., 1977; Stober et al., 1984; Lang, 1985; Starkstein et al., 1988; Bamford et al., 1989). Initial protocols using magnetic resonance imaging (MRI) techniques have supported these findings (Jernigan et al., 1991).

Cerebral metabolic profiles of patients with HD have revealed metabolic changes in the caudate nuclei which may precede the striatal atrophy seen on CT scans (Clark et al., 1986; Martin et al., 1986; Young et al., 1986, 1987, 1988; Hayden et al., 1987; Mazziotta et al., 1987). In addition, there is evidence that significant striatal hypometabolism in asymptomatic patients "at risk" for HD may even act as a presymptomatic predictor (Clark et al., 1986; Hayden et al., 1987; Mazziotta et al., 1987). In contrast, structural profiles obtained with CT scans of patients in the early stages of the disease do not commonly show pronounced deficits (Young et al., 1986, 1988). These findings suggest that in the early stages of the illness, conventional CT scan measures of basal ganglia atrophy may be relatively insensitive to alterations of neural function. 
The present study examines the relationship between neurological impairment and basal ganglia atrophy in patients with HD in the "early" and "late" clinical stages. The introduction of two additional structural indices of the more posterior regions of the basal ganglia, involving a measure of the third ventricle and a measure of a region including the lentiform nucleus, allowed for a more comprehensive approach to the investigation of this illness. Two conventional measures of caudate atrophy, the maximal distance between the frontal horns and the minimum distance between the caudate nuclei, served as more established indices of basal ganglia atrophy. The objective of this study was to determine if the correlation seen between the anterior indices and indications of disease progression could also be demonstrated with posterior structural measures.

\section{METHODS}

High resolution transaxial CT scans of the brain were carried out on patients attending the HD Research Program at the Royal Ottawa Hospital. Patients consented to participate in this study after being informed of its purpose, risks and potential benefits. All were examined neurologically and were assessed with respect to mental status prior to the onset of the study. All exhibited abnormal findings that were, on clinical grounds, consistent with HD.

All 19 study patients had a family history suggestive of HD, i.e. a progressive neurological disorder with abnormal movements and dementia present in one parent. In all cases, the family history of HD involved more than one generation.

All eight patients comprising the "late" HD group had choreiform movements involving both sides of the body, without significant evidence of involvement of any other motor systems. Also, there was evidence of dementia in five of these patients on mental status examination [Mini-Mental Status Examination (MMSE), mean \pm SD $19.3 \pm 10.1]$. Duration of illness was over 1 year in all cases.

The duration of illness was less than 1 year in the 11 patients comprising the "early" HD group. Choreiform movements were present in six of these patients. The remaining five exhibited clinically significant disorders of coordination, had quantified neurological examination (QNE; Folstein et al., 1983; Folstein, 1989) scores greater than five points and demonstrated neuropsychological impairment consistent with early HD, without incidence of overt dementia. Mean MMSE scores in the "early" group were 29.2 \pm 1.2 and significantly different from the "late" HD group $(p<0.01)$.
Clinically appropriate investigations were carried out to exclude other disorders (see Folstein, 1989, p. 141). Assessments included blood screening, EEG and CT brain scan review. The latter was carried out blind to the patient's name.

CT scans of two control groups were also included in the analysis. The first control group ("early" control) was age matched to the "early" HD group; the second group ("late" control) was aged matched to the "late" HD group (Table I). All were selected sequentially from the records of the Royal Ottawa Hospital Neuropsychiatry Program on the basis of having undergone CT head scanning but with no history or signs of significant neurological disease, and/or the abuse of drugs or alcohol (Table I). These groups were composed of patients diagnosed as suffering from affective disorders, functional psychosis, or chronic headache. In all control patients, the neurological exam was within normal limits and the score on the QNE was less than five points.

The control groups were included for comparison purposes in order to determine whether significant basal ganglia atrophy was present in the "early" HD group and, if not, whether their scans were comparable to those of neurologically normal patients. The "late" control group was included in order to determine if significant striatal atrophy occurred with age.

\section{Determination of neuroanatomical measures from CT scans}

CT scans were produced on a Picker International 1200SX machine, using sequential $10 \mathrm{~mm}$ slices, taken in the transverse plane parallel to the orbitomeatal line (Yock, 1983). The machine used has a $512 \times 512$ matrix in high resolution mode and spatial resolutions of 15 line pairs $/ \mathrm{cm}$. Scans were examined by one of the investigators who was blind to all clinical data. Those slices which best demonstrated three groups of structures on two sequential levels, approximately matching $63-70 \mathrm{~mm}$ from the brain vertex on the neuroanatomical atlas by Aquilonius and Eckernäs (1980), were selected. These structures were: (1) the caudate nuclei (at their closest proximity as they protrude into the frontal horns of the lateral ventricles), (2) the third ventricle, and (3) the structures occupying the space between the edge of the third ventricle, at its widest point, and the outermost side of the insular cortex (Fig. 1).

Levels were then digitized from the hard copy CT scan by means of a commercially available microcomputer-based image analysis system (MCID, Imaging Research St Catherines, Ontario, Canada). Color enhancement and high resolution of digitization system allowed for the precise evaluation of 
CT SCAN AND NEUROLOGICAL CORRELATES IN HUNTINGTON'S DISEASE

TABLE I. Age, sex and disease duration of patient groups

\begin{tabular}{|c|c|c|c|c|}
\hline Group & $n$ & $\begin{array}{l}\text { Mean age and } \\
\text { range (years) (S.D.) }\end{array}$ & $\begin{array}{l}\text { Number } \\
\text { of males }\end{array}$ & $\begin{array}{c}\text { Mean disease duration } \\
\text { and } \\
\text { range (years) (S.D.) }\end{array}$ \\
\hline "Early" control & 11 & $\begin{array}{c}35.4 \\
25-51(9.6)\end{array}$ & 10 & - \\
\hline "Late" control & 8 & $\begin{array}{c}58.9 \\
40-77(13.8)\end{array}$ & 3 & - \\
\hline "Early" HD & 11 & $\begin{array}{c}34.4 \\
23-60(10.7)\end{array}$ & 4 & $\begin{array}{c}0.3 \\
0-1(0.47)\end{array}$ \\
\hline “Late" HD & 8 & $\begin{array}{c}55.9 \\
43-67(7.9)\end{array}$ & 5 & $\begin{array}{c}11.1 \\
7-17(7.17)\end{array}$ \\
\hline
\end{tabular}

each CT scan image. Pertinent structures could be readily identified permitting a more precise measurement of each structure. The digitized images can achieve a resolution up to $0.1 \mathrm{~mm}$. Thus, the limiting factor of measurement accuracy was the resolution of the actual CT scan image. Seven measurements were taken from each CT scan, to produce four ratios (Fig. 1). A sample of scans was evaluated by two independent raters to allow for the calculation of indices of concordance.

\section{Neurological assessment}

The QNE was used to assess neurological impairment (Folstein et al., 1983; Folstein, 1989). The QNE yields a composite score comprising the patient's performance on a variety of tests assessing the presence and severity of choreiform movements and dystonia, and the motor skills of all parts of the body. When completing the QNE, the examiner (J.K.A.R. in all cases) was blind to all $\mathrm{CT}$ scan results. In addition to the global measure of neurological impairment (QNE-Total), three other QNE subscales were used: QNE-Chorea, as a measure of choreiform movements; the QNE-EMS, for eye movement abnormalities; and the QNE-DYST, as a measure of dystonia. These subscales were chosen for the following reasons: the chorea and eye movement abnormalities are always present in the adult HD patient and show a tendency to change in quality with disease progression (Bruyn, 1968; Folstein et al., 1986; Folstein, 1989). Dystonia tends to appear relatively late in the adult with HD (Bruyn, 1968).

The QNE-DYST scale was derived from the cumulative score on two subscales of the QNE. One subscale measured the presence of any dystonia on examination and the other axis posturing (each scored as $0=$ absent, $1=$ mild, $2=$ moderate, $3=$ severe). The higher the score on the QNE, the greater the degree of motor impairment.

Two conventional anterior measures of basal gan- glia atrophy were computed. The frontal horn ratio (FHr) was computed by dividing the maximal distance between the lateral extensions of the frontal horn by the distance between the internal tables of the skull at the point of the frontal horn measurement (FHit; Fig. 1). The bicaudate ratio (CCr) was calculated by dividing the minimum distance between the caudate nuclei by the distance between the internal tables of the skull at the point of caudate nuclei measurement (CCit). Two additional measures were calculated. The maximal width of the third ventricle was divided by $\mathrm{CCit}$ resulting in a measure of third ventricle enlargement $(3 \mathrm{Vr})$. The sum of the distance between the walls of the third ventricle at its widest point and the outer edge of the insular cortex was divided by the CCit to obtain a measure of atrophy of this region. Dividing each neuroanatomical measure by the measurement of the internal table of the skull reduced the possibility of a confounding effect of variation in skull size.

The comparison of the CT measures with the neuroanatomical atlas (Aquilonius and Eckernäs, 1980) indicated that the frontal horn ratio $(\mathrm{FHr})$ and bicaudate ratio $(\mathrm{CCr})$ measures accurately reflected changes in the region of the head of the caudate nucleus.

The third ventricle ratio $(3 \mathrm{Vr})$ and lentiform ratio (LENTIr) measures represented more posterior regions, including the thalamus, internal and external capsules, globus pallidus and putamen and served as non-conventional measures.

\section{Data analysis}

Data were analysed with analysis of variance techniques (ANOVA) and, where appropriate, with correlational indices. Post-hoc comparisons were performed by Student-Newman-Keuls tests of significance. Group membership ("early" control, "late" control, "early" HD and "late" HD) was treated as the independent variable for the purposes of the 


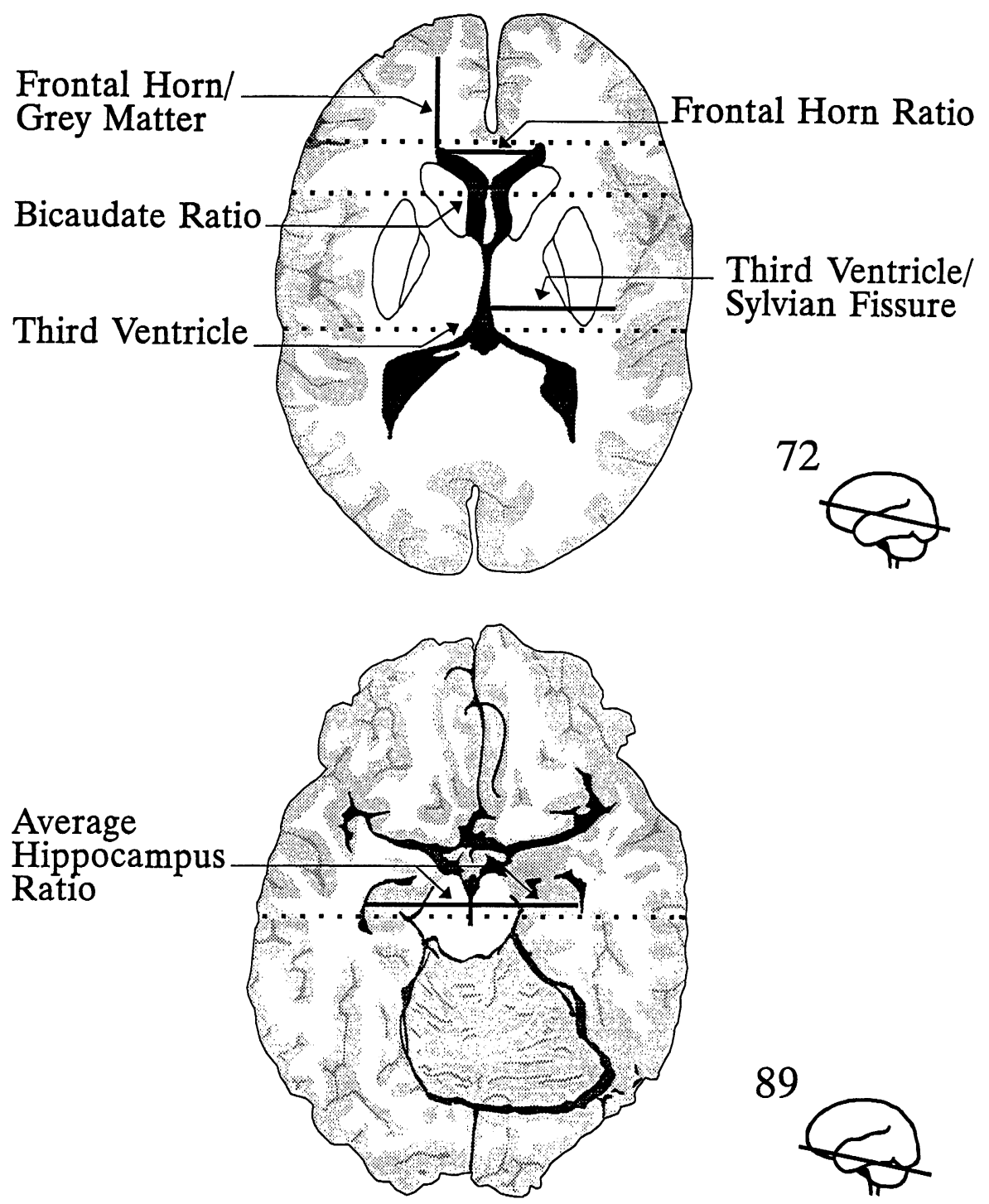

FIG. 1. Neuroanatomical measures used. FHit is the distance between the internal tables of the skull on a line drawn through the tips of the frontal horns. FH is the maximal distance between the tips of the frontal horns. Frontal horn ratio (FHr) is determined by dividing FH by FHit. CCit is the distance between the internal tables of the skull taken at the point at which the medial edges of the caudate nuclei are closest. $\mathrm{CC}$ is the minimal distance between the caudate nuclei. Bicaudate ratio (CCr) is $\mathrm{CC}$ divided by CCit. $3 \mathrm{~V}$ is the measure of the maximum width of the third ventrical. Third ventricle ratio ( $3 \mathrm{Vr}$ ) is $3 \mathrm{~V}$ divided by CCit. LENTI is the distance between the edge of the third ventricle at its widest point and the outer edge of insular cortex. Both the left and right LENTI measures are combined, and the sum is taken to produce a single value. Lentiform ratio (LENTIr) is LENTI divided by CCit.

analysis of variance but the "early" and the "late" HD groups were combined in the context of the correlational evaluations (Tabachnick and Fidell, 1989).

\section{RESULTS}

Analysis of CT scan measurements

All measures of the basal ganglia proved to be signifi- cantly smaller in the "late" HD group, when compared with its control and "early" groups. The four ratio measures (see Fig. 1) taken from the CT scans were first compared for the four groups by means of an ANOVA (Tabachnick and Fidell, 1989). Significant overall effects (range $p \leqq 0.006$ to $p \leqq 0.0001$ ) were further evaluated by post-hoc tests. For all measures, significant differences were found between the "early" control, "late" control and "early" HD 
CT SCAN AND NEUROLOGICAL CORRELATES IN HUNTINGTON'S DISEASE

TABLE II. Group means and standard deviations (S.D.) of the neuroanatomical measures of the HD patients

\begin{tabular}{lcccc}
\hline Group & $\begin{array}{c}\text { "Early" } \\
\text { control }\end{array}$ & $\begin{array}{c}\text { "Late" } \\
\text { control }\end{array}$ & $\begin{array}{c}\text { "Early" } \\
\text { HD }\end{array}$ & $\begin{array}{c}\text { "Late" } \\
\text { HD }\end{array}$ \\
$\begin{array}{l}\text { Correlation of } \\
\text { measures with } \\
\text { illness duration }\end{array}$ \\
\hline FHr & 0.312 & 0.314 & 0.291 & $0.62^{* *}$ \\
S.D. & 0.033 & 0.029 & 0.040 & 0.034 \\
CCr & 0.113 & 0.112 & 0.112 & 0.171 \\
S.D. & 0.022 & 0.023 & 0.030 & 0.046 \\
3Vr & 0.034 & 0.033 & 0.070 \\
S.D. & 0.010 & 0.006 & 0.009 & 0.022 \\
LENTIr & 0.646 & 0.631 & 0.660 & 0.589 \\
S.D. & 0.042 & 0.030 & 0.046 & 0.041 \\
\hline
\end{tabular}

"Early" HD vs controls ("early" and "late"): no significant differences between group means for any measures.

"Late" HD vs "early" HD: group means differ significantly $(p<0.05)$ on all measures.

Correlations between neuroanatomical measures and duration of disease: ${ }^{\star} p \leqq 0.05 ;{ }^{* \star} p \leqq 0.01 ;{ }^{\star \star \star} p \leqq 0.001$.

TABLE III. Intercorrelations of neuroanatomical measures

\begin{tabular}{lcccc}
\hline & $\mathrm{FHr}$ & $\mathrm{CCr}$ & LENTIr & \multicolumn{1}{c}{$3 \mathrm{Vr}$} \\
\hline $\mathrm{FHr}$ & - & 0.56 & -0.69 & 0.82 \\
CCr & 0.05 & - & -0.86 & -0.53 \\
LENTIr & 0.001 & 0.001 & - & -0.76 \\
3Vr & 0.001 & 0.008 & 0.001 & - \\
\hline
\end{tabular}

Values on top right diagonal represent correlations of measures for the "early" and "late" HD groups $(n=20)$. Values at bottom left represent level of statistical probability of correlation.

groups when compared with the "late" HD group. However, no statistically significant differences were found between control and "early" HD groups $(p>0.05$; Table II).

Combination of the "early" and "late" HD groups increased the variation in the disease duration range which allowed for the determination of correlations between striatal structure size and illness duration. Results indicated that the FHr, $3 \mathrm{Vr}$ and LENTIr measures were significantly correlated with disease duration. The $\mathrm{CCr}$ measure, while statistically significant, evidenced the relatively lowest association with illness duration (Table II).

All measures were intercorrelated to determine the unique contribution of each. All were strongly correlated; none of the associations shared more than $65 \%$ of common variance ( $r=-0.74$; Table III).

In order to determine the precision of the measurements taken, three scans were redigitized and the measurements were repeated by two of the investigators, who were blind to each other's scores. Agreement between measurements of both raters was determined by calculating the mean of difference in the measurements taken by each observer. The mean measurement error was calculated to be $1.09 \mathrm{~mm}$
$( \pm 1.48 \mathrm{~mm}$ ) using the method described in Bland and Altman (1986).

\section{Neurological measures}

Comparison of measures of neurological abnormality in the HD patients indicated, as expected, substantial differences between the "early" and "late" HD groups. Analysis of variance revealed a significant impairment in motor function in the "late" HD group. This group was impaired on all four QNE measures (QNE-Total, QNE-Chorea, QNE-EMS, QNE-DYST) relative to the "early" HD group ( $p \leqq 0.001$; Table IV). Correlations between disease duration and increasing abnormality in motor function (as measured by QNE) was demonstrated on all four motor measures $(p \leqq 0.01$; Table IV).

These motor measures remained significantly correlated with disease duration when the "early" and "late" HD groups were combined (Spearman's correlation coefficients $r=0.47$ to $0.86, p<0.001$ for all except QNE-DYST where $p \leqq 0.05$.)

\section{Concomitant variation of neuroanatomical and neurological changes}

Comparisons of the QNE scales with neuroanatomical measures for both the "early" and "late" HD groups demonstrated that the QNE measures were strongly correlated with striatal atrophy for several comparisons. However, the strength of association varied in the "early" and "late" HD groups. For example, the bicaudate ratio measure $(\mathrm{CCr})$ was best correlated with alterations in motor function in the "early" HD group ( $r=0.57$ to 0.64 ; Table $\mathrm{Va}$ ), while the lentiform region measure (LENTIr) was highly correlated with altered motor function in the "late" HD sample $(r=0.78$ to 0.89 ; Table $\mathrm{Vb})$. 
TABLE IV. QNE measures, group means and standard deviations (S.D.)

\begin{tabular}{lccc}
\hline & "Early" HD & "Late" HD & $\begin{array}{c}\text { Correlation } \\
\text { with } \\
\text { duration }\end{array}$ \\
\hline QNE-Total & 10.18 & 69.67 & $0.76^{\star \star \star}$ \\
(S.D.) & $(10.66)$ & $(32.45)$ & \\
QNE-Chorea & 1.91 & 16.00 & $0.86^{\star \star \star}$ \\
(S.D.) & $(2.70)$ & $(5.34)$ & \\
QNE-EMS & 1.36 & 8.22 & $0.80^{\star \star \star}$ \\
(S.D.) & $(1.86)$ & $(2.91)$ & $0.45^{\star}$ \\
QNE-DYST & 0.09 & 2.22 & \\
(S.D.) & $(0.30)$ & $(2.54)$ & \\
\hline
\end{tabular}

In all cases, "late" stage group means are statistically significantly different from "early" ( $p \leqq 0.001)$. Last column represents correlations between functional measure and duration of disease: ${ }^{*} p \leqq 0.05 ;{ }^{* * *} p \leqq 0.001$.

TABLE Va. Correlations between QNE movement impairment indices and neuroanatomical atrophy in "early" HD $(n=11)$

\begin{tabular}{lrrrr}
\hline & $\mathrm{FHr}$ & $\mathrm{CCr}$ & $3 \mathrm{Vr}$ & LENTIr \\
\hline QNE-Total & -0.14 & 0.24 & 0.15 & -0.37 \\
QNE-Chorea & 0.30 & 0.31 & 0.47 & -0.38 \\
QNE-EMS & -0.07 & 0.13 & 0.10 & -0.45 \\
QNE-DYST & 0.20 & 0.33 & 0.02 & -0.22 \\
\hline
\end{tabular}

No significant correlations.

TABLE Vb. Correlations between QNE movement impairment indices and neuroanatomical atrophy in "late" HD $(n=9)$

\begin{tabular}{lllll}
\hline & $\mathrm{FHr}$ & \multicolumn{1}{c}{$\mathrm{CCr}$} & \multicolumn{1}{c}{$3 \mathrm{Vr}$} & LENTIr \\
\hline QNE-Total & $0.65^{*}$ & $0.62^{*}$ & 0.51 & $-0.90^{\star \star \star}$ \\
QNE-Chorea & 0.47 & $0.76^{* *}$ & 0.35 & $-0.86^{\star *}$ \\
QNE-EMS & $0.86^{\star *}$ & 0.44 & $0.74^{\star}$ & $-0.79^{*}$ \\
QNE-DYST & $0.71^{*}$ & $0.74^{*}$ & 0.44 & $-0.90^{* \star}$ \\
\hline
\end{tabular}

${ }^{*} p \leqq 0.05 ;{ }^{* *} p \leqq 0.01 ;{ }^{* \star \star} p \leqq 0.001$.

\section{DISCUSSION}

In this study, the comparison between CT scan measures in control, "early" and "late" HD groups indicated that a significant amount of brain atrophy was evident in the "late" HD group, compared with all other groups, for all regions examined. This suggests that the measures employed here are sensitive to neuroanatomical changes related to the progression of HD. Further, no statistically significant differences were found when the CT measures from the "early" HD and "early" and "late" control groups were compared (Table II). This finding supports the proposal that individuals in the "early" group are dis- tinct from the "late" HD group of patients and could suggest that there is no structural change that can be identified in these "early" HD scans by the methods used in this study. Alternatively, these findings might be interpreted to suggest that "early" HD patients did in fact not have active disease, although the clinical criteria would suggest otherwise.

The conventional "anterior" CT scan measures of basal ganglia atrophy $(\mathrm{FHr}, \mathrm{CCr})$ as well as the two "posterior" measures (3Vr, LENTIr) all appeared to be sensitive to structural alterations associated with the progression of HD. All four CT measures were significantly correlated with disease duration. While the third ventricle measure $(3 \mathrm{Vr})$ proved to be most strongly correlated with disease duration, the commonly used measure of bicaudate ratio $(\mathrm{CCr})$ demonstrated a more modest association with duration.

Findings utilizing the conventional "anterior" measures were in keeping with previous reports (Stober et al., 1984; Starkstein et al., 1989). The "posterior" measures proved to be equally efficacious indicators of disease progression.

Other studies utilizing the CT brain scanner have made it possible to correlate the degree of caudate atrophy with the clinical features of HD. "Anterior" measures, such as intercaudate distance, have been found to have a significant correlation with disease severity (Shoulson, 1981; Sax et al., 1983; Stober et al., 1984), and it has been suggested that the frontal horn/bicaudate ratio could predict the presence of clinical disease (Sax and Menzer, 1977; Terrence et al., 1977; Barr et al., 1978; Oepen and Osterlag, 1981; Stober et al., 1984; Lang, 1985; Mazziotta, 1989).

The present data support the hypothesis that "posterior" measures (LENTIr, 3Vr) may also be useful correlates of disease progression. Further support for using "posterior" measures is found in a paper by Harris et al. (1992). Using the MRI scanner, this study ascertained that putaminal size was more closely correlated with the presence of disease than caudate size in patients with early HD.

The progression of HD in adults is associated with progressive worsening of choreiform movements, especialy during the first 10 years of the illness (Bruyn, 1968; Folstein et al., 1986; Folstein, 1989). Therefore, it is to be expected that the QNE-Chorea score correlates significantly with illness duration (Table IV). A similar correlation was also expected and obtained for QNE-EMS, as eye movement abnormalities show increasing severity as the disease progresses (Bruyn, 1968; Folstein et al., 1986; Folstein, 1989).

Overall, the QNE measures appear to be sensitive to the degree of motor disability and each of the QNE measures significantly correlated with disease 
duration (Table IV). Thus, it appears appropriate to compare the neurological measures with indices of basal ganglia atrophy and obtain meaningful comparisons.

No significant correlations were found, in the "early" group, when QNE scores and specific CT measures were compared (Table Va). This is not surprising as no significant differences were found between CT measures in the "early" HD group and the controls (Table II). In the "late" HD group on the other hand, all the CT measures were correlated with at least one of the QNE scores. In this group, the LENTIr was the only measure that correlated significantly with all the QNE scores (see Table Vb). It is suggested that the LENTIr is, to a large extent, measuring putamen size (Harris et al., 1992). Hence, in light of the evidence that the putamen regions receive input related mainly to motor function (Alexander $e t$ al., 1986; Alexander and Crutcher, 1990), the LENTIr findings may reflect the significant role of this structure in the motor symptoms of $\mathrm{HD}$, a contention also postulated by PET scan investigations (Young et al., 1986; Mazziotta, 1989). Anterior measures in turn may be less significant in this context as they showed a more variable correlation with the QNE scores.

Dystonia, on the other hand, becomes more pronounced in the later stages, tending to replace the hyperkinetic activity (Bruyn, 1968), and so is less well correlated with illness duration, as was observed in the current study.

It is further notable that the correlations found between the $3 \mathrm{Vr}$ and the LENTIr measures differ. There was a dramatic correlation between LENTIr and the QNE measures, and a lesser correlation between the $3 \mathrm{Vr}$ and QNE measures (see Tables $\mathrm{Va}$ and $\mathrm{Vb}$ ). In contrast, compared with the LENTIr, the $3 \mathrm{Vr}$ was found to correlate to a marginally greater extent with illness duration (Table II). Thus, it may be that the third ventricle changes are, at least in part, the result of a different process and so have a separate significance. When the LENTIr and $3 \mathrm{Vr}$ measures were correlated, a significant correlation coefficient was obtained, indicating a concomitant variation of slightly more than $50 \%$. Thus slightly less than half of the variation of one measure could not be explained by the other. This again suggests that the two measures were assessing atrophy in similar but not identical regions. Hence the evidence supports changes in the $3 \mathrm{Vr}$ as being independent of those found in the LENTIr.

It should be noted that the enlargement of the third ventricle is predominantly lateral and other investigators have utilized linear measurements as an adequate representation of ventricular size (Shelton and Weinberger, 1986). On the basis of its anatomical relationships, the $3 \mathrm{Vr}$ changes may reflect changes in the thalamus, which have been noted in other studies of HD (Carter et al., 1989; Mazziotta, 1989). Other authors have indicated that third ventricle enlargement appears to be a result of striatal atrophy rather than a passive reflection of enlargement of the whole cerebral ventricular system (Boronow et al., 1985).

In summary, current results suggest that neurological abnormalities in HD are related to atrophy of the posterior, as well as the anterior regions of the basal ganglia. The present study demonstrates that along with the additional measures of striatal atrophy ( $\mathrm{FHr}$, $\mathrm{CCr}$ ), measures of the third ventricle ( $3 \mathrm{Vr})$ and lentiform regions (LENTIr) may be equal, if not better, correlates of neurological decline. With the utilization of these two measures of the posterior basal ganglia regions, it may be possible, in subsequent studies, to obtain a better understanding of the progression of basal ganglia atrophy and its relationship to neurological dysfunction.

\section{Acknowledgements}

We wish to gratefully acknowledge the technical contributions of Ms Sharon Sally to this study. The authors would also like to thank the Royal Ottawa Research Foundation for financial support for this project, and Dr Bruce Pappas, Department of Psychology, Carleton University, Ottawa, for the use of his image digitization equipment. The figure was prepared by Ms Margaret Sampson.

\section{REFERENCES}

Alexander GE and Crutcher MD (1990) Functional architecture of basal ganglia circuits: Neural substrates of parallel processing. Trends in Neurosciences, 13, 266-271.

Alexander GE, DeLong MR and Strick PL (1986) Parallel organization of functionally segregated circuits linking basal ganglia and cortex. Annual Review of Neuroscience, 9, 357-381.

Aquilonius SM and Eckernäs SA (1980) A Colour Atlas of the Human Brain. Raven Press, New York.

Bamford KA, Caine ED, Kido DK, Plassche WM and Shoulson I (1989) Clinical-pathologic correlation in Huntington's disease: A neuropsychological and computed tomography study. Neurology, 39, 796-801.

Barr A, Heinze W, Dobben G, et al. (1978) Bicaudate index in computerized tomography of Huntington's disease and cerebral atrophy. Neurology, 28, 1196-1200.

Bland JM and Altman DG (1986) Statistical methods for assessing agreement between two methods of clinical measurement. Lancet, 1, 307-310.

Boronow J, Pickar D, Ninan PT, Roy A, Hommer D, Linnoila M and Paul SM (1985) Atrophy limited to the third ventricle in chronic schizophrenic patients. Report of a controlled series. Archives of General Psychiatry, 42, 266-271.

Bruyn GW (1968) Huntington's chorea: Historical, clinical and laboratory synopsis. In: Handbook of Clinical Neurology, Vol. 6, Diseases of the Basal Ganglia (Eds PJ Vinken

Behavioural Neurology • Vol 7 . 1994 
and EW Bruyn), pp. 298-378. North-Holland, Amsterdam.

Bruyn G (1973) Huntington's chorea. In: Huntington's Chorea (Eds A Barbeau, G Paulson and T Chase), pp. 399-403. Raven Press, New York.

Carter CJ, Benavides J and Dubois A (1989) The biochemistry of Huntington's chorea. In: Disorders of Movement (Eds NP Quinn and PG Jenner), pp. 469-494. Academic Press, San Diego.

Clark CM, Hayden MR, Stoessl AJ and Martin MRW (1986) Regional perfusion model for predicting dissociations of regional cerebral glucose metabolism in individuals at risk for Huntington's disease. Journal of Cerebral Blood Flow and Metabolism, 6, 756-762.

Folstein SE (1989) Huntington's Disease: A Disorder of Families. The John Hopkins University Press, Baltimore, MD.

Folstein SE, Jensen B, Leigh J and Folstein MF (1983) The measurement of abnormal movement: Methods developed for Huntington's disease. Neurobehavioral Toxicology and Teratology, 5, 605-609.

Folstein SE, Leigh J, Parhad IM and Folstein MF (1986) The diagnosis of Huntington's disease. Neurology, 36, 1279-1283.

Harris GJ, Pearlson GD, Peyser CE, Aylward EH, Roberts J, Barta PE, Chase GA and Folstein SE (1992) Putamen volume reduction on magnetic resonance imaging exceeds caudate changes in mild Huntington's disease. Annals of Neurology, 31, 69-75.

Hayden MR, Hewitt J and Stoessl AJ (1987) The combined use of positron emission tomography and DNA polymorphisms for preclinical detection of Huntington's disease. Neurology, 37, 1441-1447.

Jernigan TL, Salmon DP, Butters N and Hesselink JR (1991) Cerebral structure on MRI, Part II: Specific changes in Alzheimer's and Huntington's diseases. Biological Psychiatry, 29, 68-81.

Lang C (1985) Is direct CT caudatometry superior to indirect parameters in confirming Huntington's disease? Neuroradiology, 27, 161-163.

Martin WRW, Stoessl AJ, Adam MJ, et al. (1986) Positron emission tomography in Parkinson's disease: glucose and dopa metabolism. Archives of Neurology, 45, 9598.

Mazziotta JC (1989) Huntington's disease: Studies with structural imaging techniques and positron emission tomography. Seminars in Neurology, 9, 360-369.

Mazziotta JC, Phelps ME, Pahl JJ, Huang SC, Baxter LR, Reige WH, Hoffman JM, Kuhl DE, Lanto AB, Wapenski JA and Markham CH (1987) Reduced cerebral glucose metabolism in asymptomatic subjects at risk for Huntington's disease. New England Journal of Medicine, 316, 357-362.

Oepen G and Osterlag CH (1981) Diagnostic value of CT in patients with Huntington's disease and their offspring. Journal of Neurology, 225, 189-196.

Roos RA, Pruyt JF, de Vries J and Bots GT (1985) Neuronal distribution in the putamen in Huntington's disease. Journal of Neurology, Neurosurgery and Psychiatry, 48, 422-425.
Sax DS and Menzer L (1977) Computerised tomography in Huntington's disease. Neurology, 27, 388 (abstract).

Sax DS, O’Donnell B, Butters N, Menzer L, Montgomery $\mathrm{K}$ and Kayne HL (1983) Computed tomographic, neurologic and neuropsychological correlates of Huntington's disease. International Journal of Neuroscience, 18, 21-36.

Shelton RC and Weinberger DR (1986) X-ray computerised tomography studies in schizophrenia: a review and synthesis. In: The Neurology of Schizophrenia (Eds HA Nasrallah and DR Weinberger), pp. 207-250. Elsevier, Amsterdam.

Shoulson I (1981) Huntington's disease: functional capacity in patients treated with neuroleptic and antidepressant drugs. Neurology, 31, 1333-1335.

Starkstein SE, Brandt J, Folstein S, Strauss M, Berthier ML, Pearlson GD, Wong D, McDonnell A and Folstein M (1988) Neuropsychological and neuroradiological correlates in Huntington's disease. Journal of Neurology, Neurosurgery and Psychiatry, 51, 1259-1263.

Starkstein SE, Folstein SE, Brandt J, Pearlson GD, McDonnell A and Folstein M (1989) Brain atrophy in Huntington's disease. A CT-scan study. Neuroradiology, 31, 156159 .

Stober T, Wussow W and Schimrigk K (1984) Bicaudate diameter-the most specific and simple CT parameter in the diagnosis of Huntington's disease. Neuroradiology, 26, 25-28.

Tabachnick BG and Fidell LS (1989) Using Multivariate Statistics, 2nd edn. Harper \& Row Publishers, Cambridge.

Terrence CF, Delaney JF and Alberts MC (1977) Computed tomography for Huntington's disease. Neuroradiology, 13, 173-175.

Vonsattel JP, Myers RH, Stevens TJ, Ferrante RJ, Bird ED and Richardson EP Jr (1985) Neuropathological classification of Huntington's disease. Journal of Neuropathology and Experimental Neurology, 44, 559-577.

Yock DH (1983) Techniques in imaging of the brain. Part 1: The skull. In: The Clinical Neurosciences: Neuroradiology (Eds RN Rosenberg and ER Heinz), p. 3. Churchill Livingstone, New York.

Young AB, Penney JB, Starosta-Rubinstein S, Markel DS, Berent S, Giordani B, Ehrenkaufer R, Jewett D and Hichwa R (1986) PET scan investigations of Huntington's disease: cerebral metabolic correlates of neurological features and functional decline. Annals of Neurology, 20, 296-303.

Young AB, Penney JB, Starosta-Rubinstein S, Markel D, Berent S, Rothley J, Betley A and Hichwa R (1987) Normal caudate glucose metabolism in persons at risk for Huntington's disease. Archives of Neurology, 44, 254-257. Young AB, Penney JB, Markel DS, Hollingsworth Z, Teener J, Stern J, Gusella J, St George-Hyslop P, Hobbs W, Rothley J and Betley A (1988) Genetic linkage analysis, glucose metabolism, and neurologic examination: comparison in persons at risk for Huntington's disease (HD). Neurology, 38(Suppl 1), 359 (abstract).

(Received 20 March 1994; accepted as revised 19 October 1994) 


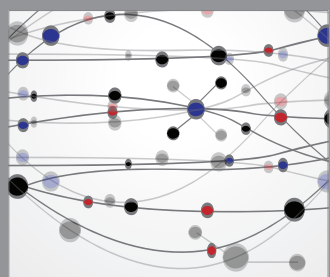

The Scientific World Journal
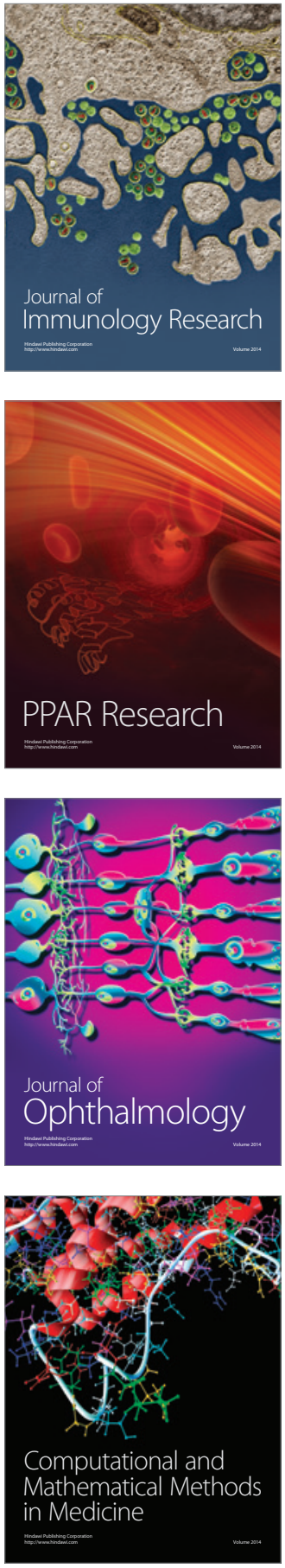

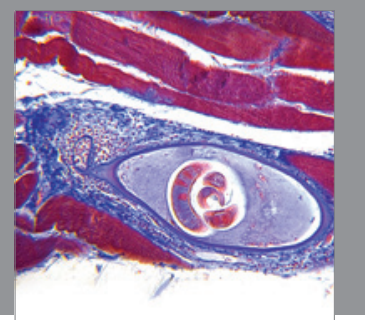

Gastroenterology

Research and Practice
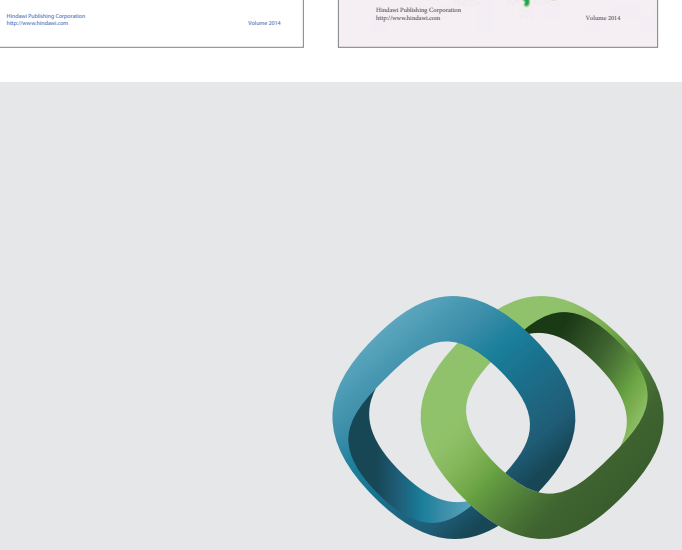

\section{Hindawi}

Submit your manuscripts at

http://www.hindawi.com
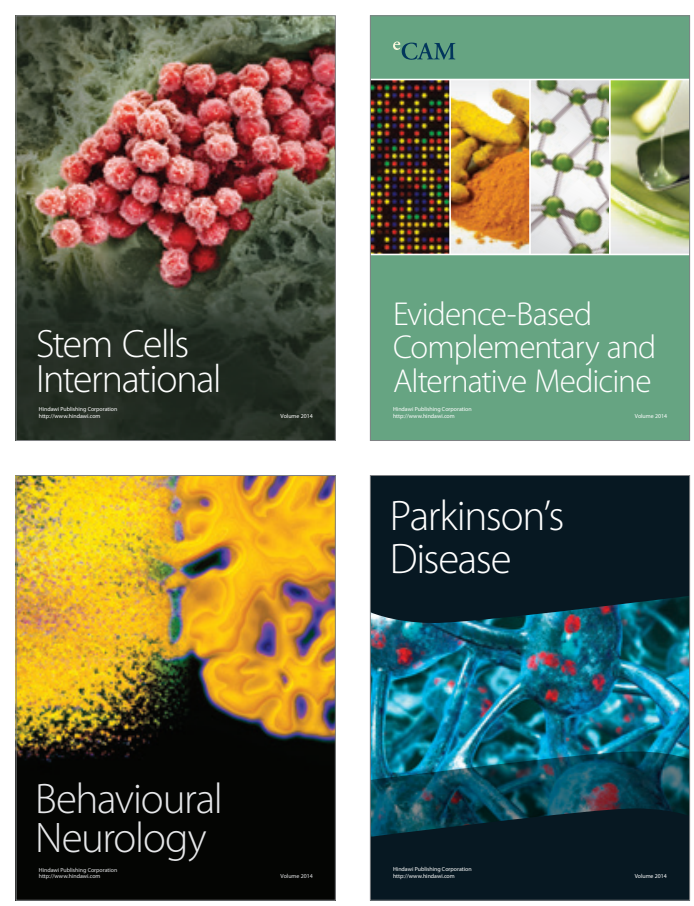

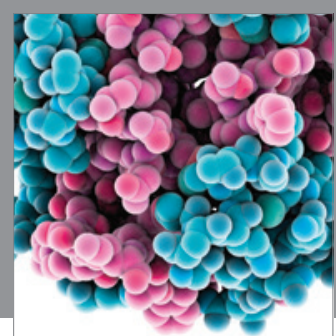

Journal of
Diabetes Research

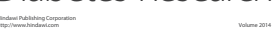

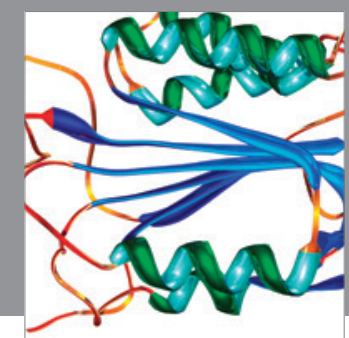

Disease Markers
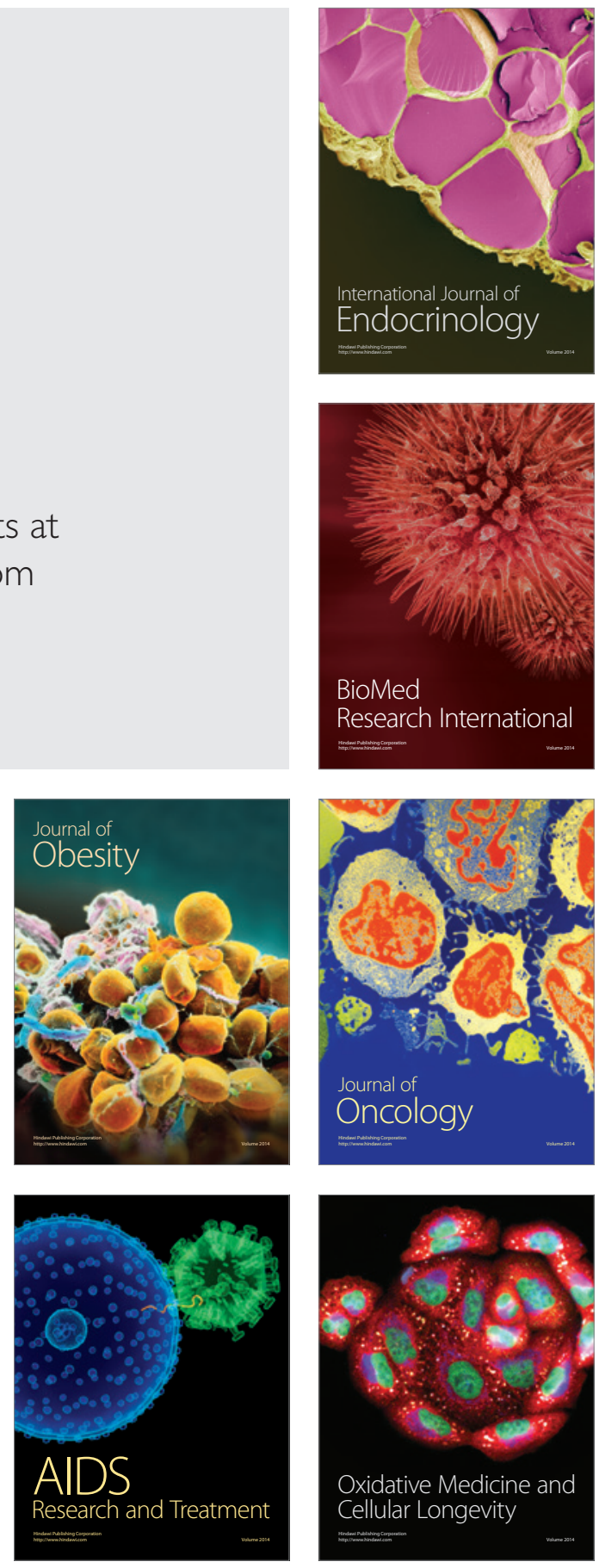